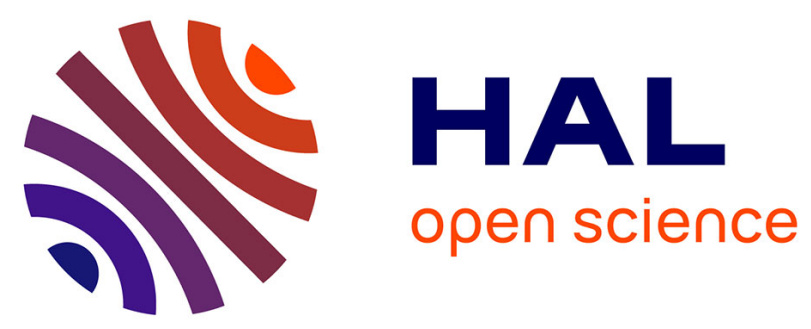

\title{
Very accurate explicit approximations for calculation of the Colebrook friction factor Žarko Ćojbašić, Dejan Brkić
}

\section{To cite this version:}

Žarko Ćojbašić, Dejan Brkić. Very accurate explicit approximations for calculation of the Colebrook friction factor. International Journal of Mechanical Sciences, 2013, 67, pp.10-13. 10.1016/j.ijmecsci.2012.11.017 . hal-01586527

\section{HAL Id: hal-01586527 https://hal.science/hal-01586527}

Submitted on 13 Sep 2017

HAL is a multi-disciplinary open access archive for the deposit and dissemination of scientific research documents, whether they are published or not. The documents may come from teaching and research institutions in France or abroad, or from public or private research centers.
L'archive ouverte pluridisciplinaire HAL, est destinée au dépôt et à la diffusion de documents scientifiques de niveau recherche, publiés ou non, émanant des établissements d'enseignement et de recherche français ou étrangers, des laboratoires publics ou privés. 
Elsevier Editorial System(tm) for

International Journal of Mechanical Sciences

Manuscript Draft

Manuscript Number: IJMS-111051R2

Title: Very accurate explicit approximations for calculation of the colebrook friction factor

Article Type: Research Paper

Corresponding Author: Dr Dejan Brkic, PhD in Petroleum Eng.

Corresponding Author's Institution:

First Author: Zarko Cojbasic, PhD in Mechanical Eng.

Order of Authors: Zarko Cojbasic, PhD in Mechanical Eng.; Dejan Brkic, PhD in Petroleum Eng. 


\author{
Žarko Ćojbašić \\ Dejan Brkić \\ Corresponding author e-mail: \\ dejanbrkic0611@gmail.com
}

$17^{\text {th }}$ October 2012

Professor M. Wiercigroch

Journal Editor

International Journal of Mechanical Sciences

Dear Professor Wiercigroch,

Along with the revised version R2 of the manuscript IJMS-111051R2 by Ž. Ćojbašić and D. Brkić which is submitted through online system, enclosed please find responses to the comments of the reviewers to the previous revised version R1 of the paper.

First of all, authors would like to express their gratitude to you, professor Reid and the reviewers for valuable comments and remarks along the review process, which helped us to improve the paper quality.

Althoug reviewer \#1 had no further suggestions and reviewer \#2 suggested minor improvements (at the same time proposing positive decision and not demanding that paper is further returned to him), every effort has been made to fully embrace the final recommendations.

\section{Comments of the Reviewer \#1.}

GENERAL: The authors presented a revised version of the paper with considering large number of revisions pointed out in the first review. Revisions are sufficiently clarified by the authors' closure letter, this makes easy to follow the advances on the revised manuscript, with respect to the firstly submitted version. In the revised submission, the revised text is now more suitable to readily follow its technical content; the references were extended to cite previous works. In my opinion, further revisions don't required from now; so, its current revised version is just suitable for publication as a "technical note" in the Journal.

ANSWER: No further changes were suggested by the reviewer \#1. 


\section{Comments of the Reviewer \#2.}

GENERAL: Authors reports most of the changed required by this reviewer. Nonetheless there are some minor comments which need to be addressed before final acceptance.

This work does not need additional round from this reviewer.

POINT 1: In section 2, page 3, line 56: why lambda and lambda_0 are evaluated in MS Excel? The part in brackets does not make sense to me without an explanation and it should be deleted.

ANSWER: The mentioning of MS Excel was motivated by our previous paper regarding usage of this software for efficient Colebrook friction factor calculation. However, we approved reviewer's opinion and to avoid any confusion among the readers we have deleted text in brackets in sentence on page 3 - '(additionally, $\lambda$ and $\lambda_{0}$ were evaluated in MS Excel [9])'.

POINT 2: Page 4, line 41-56: it is still not clear which kind of distribution of sampling point the authors considered. They state that a uniform distribution could be misleading but do not actually declare their sampling strategy.

ANSWER: This has been further clarified by adding explicit statement regarding sampling of the points in the input space defined by the domains of input variables. Text now includes the following sentence altered from R1 verson of the paper: "This area is covered with 740 points uniformly sampled over the ranges of input variables, which means that estimated error can be slightly above (somewhere among four adjacent tested points of the matrix which consists of 740 points)."

POINT 3: Finally, the concluding section contains two timed the reference to Giustolisi et al. [22]. In my previous comments I just noticed some discrepancy with actual paper content but it was not my intention to emphasize that paper everywhere through the text. I suggest to move the last sentence of conclusions to the introductory section where it would fit better.

ANSWER: Last sentence of the conclusion has been moved to introductory part of the paper.

POINT 4: Authors' answer to my question (POINT 4):

"Indeed, we do plan to extend methodology and present more results and wider discussion in future publication. But here, we focus on most accurate approximations that we have obtained during much wider research that considered most of the approximations published to date, in order to offer improved accuracy for explicit pipe flow friction calculation. We do focus on this aspect and neglect others in the paper as we believe that accuracy is of primary interest for both researchers in the field and practical applications."

Should be somehow reported in the conclusions 


\begin{abstract}
ANSWER: We have included this in the conclusion, by adding one final sentence regarding further research potentials beyond the results presented in this paper. 'Beyond the most accurate optimized approximations that we have presented here, genetic optimization methodology can be applied to the wider set of the approximations for explicit pipe flow friction calculation published to date, in order to offer improved accuracy with possibly other computational benefits.'
\end{abstract}

We hope that you will find that we have provided paper improvements that were suggested and we are looking forward to hearing from you soon and publishing of our paper.

Yours sincerely, Authors 
-Original Colebrook equation for flow friction is implicit in unknown flow friction factor

-Two very accurate explicit approximations for calculation of the Colebrook friction factor are shown

-New equations are with the maximal relative error of no more than $0.0083 \%$ and $0.0026 \%$

-Already existed models were improved using genetic algorithm optimization technique

-Accuracy is improved 53.26 and 16.2 times with no additional computational burden 
Graphical Abstract (for review)

Model A:

$\frac{1}{\sqrt{\lambda}} \approx S_{1}-\frac{\left(S_{2}-S_{1}\right)^{2}}{S_{3}-2 \cdot S_{2}+S_{1}}$

$S_{1}=-2 \cdot \log _{10}\left(\frac{\varepsilon}{3.71 \cdot D}+\frac{12.585}{R e}\right) ; \quad S_{2}=-2 \cdot \log _{10}\left(\frac{\varepsilon}{3.71 \cdot D}+\frac{2.51 \cdot S_{1}}{R e}\right) ; \quad S_{3}=-2 \cdot \log _{10}\left(\frac{\varepsilon}{3.71}\right.$
Model B:
$\frac{1}{\sqrt{\lambda}} \approx-2 \cdot \log _{10}\left(\frac{\varepsilon}{3.7106 \cdot D}-\frac{5}{R e} \cdot \log _{10}\left(\frac{\varepsilon}{3.8597 \cdot D}-\frac{4.795}{\operatorname{Re}} \cdot \log _{10}\left(\left(\frac{\varepsilon}{7.646 \cdot D}\right)^{0.9685}+\left(\frac{4.9755}{206.2795+R e}\right)^{0.8759}\right)\right)\right)$

$\lambda$-Darcy friction factor, Re-Reynolds number, $\varepsilon / D$-relative roughness 


\title{
Very accurate explicit approximations for calculation of the Colebrook friction factor
}

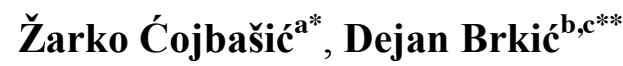

${ }^{\mathrm{a} U n i v e r s i t y ~ o f ~ N i s ̌, ~ F a c u l t y ~ o f ~ M e c h a n i c a l ~ E n g i n e e r i n g ~ i n ~ N i s ̌, ~ A l e k s a n d r a ~ M e d v e d e v a ~ 14, ~}$ 18000 Niš, Serbia

${ }^{\mathrm{b}}$ University of Novi Sad, Faculty of Technology, Bulevar Cara Lazara 1, 21000 Novi Sad, Serbia

${ }^{\mathrm{c} S t r u m i c ̌ k a ~ 88, ~} 11050$ Belgrade, Serbia

\begin{abstract}
To date, the Colebrook equation is mostly accepted as an unofficial standard for calculation of the friction factor in turbulent flow through pipes. Unfortunately, the unknown friction factor in the Colebrook equation is given implicitly. Therefore, the implicit Colebrook equation has to be solved in an iterative procedure or using some of the appropriate explicit correlations proposed by many authors. Although the iterative solution is simple and very accurate, it can cause some problems during the calculation of looped network of pipes or similar systems of pipes. Therefore, explicit approximations are favorable in these cases. Up to date, the most accurate approximations have maximal relative error of no more than $0.14 \%$ compared to the very accurate iterative solution. Here two explicit approximations are presented, based on already existing models which are improved using genetic algorithms optimization. They are with the maximal relative error of no more than $0.0083 \%$ and $0.0026 \%$.
\end{abstract}

Keywords: Colebrook equation; Colebrook-White equation, Flow friction; Hydraulic resistance; Genetic algorithms; Optimization technique

\footnotetext{
* cell: +381638351936, e-mail: zcojba@ni.ac.rs (Žarko Ćojbašić) ** cell: +381642543668, e-mail: dejanrgf@tesla.rcub.bg.ac.rs, dejanbrkic0611@gmail.com (Dejan Brkić)
} 


\section{Introduction}

The Colebrook equation is nowadays mostly used for computing of the turbulent flow friction in pipes [1]. It was developed solely by Colebrook in 1939 [1], but he also used the data from his joint experiment with White from 1937 [2]. Therefore, his equation is sometimes referred as the Colebrook-White equation. Unfortunately, in this equation unknown friction factor $\lambda$ is given implicitly (1):

$$
\frac{1}{\sqrt{\lambda}}=-2 \cdot \log _{10}\left(\frac{2.51}{\operatorname{Re} \cdot \sqrt{\lambda}}+\frac{\varepsilon}{3.71 \cdot D}\right)
$$

where $\lambda$ is the Darcy friction factor (known also as the Darcy-Weisbach or Moody friction factor), Re is the Reynolds number, and $\varepsilon / \mathrm{D}$ is relative roughness of inner pipe surface. All mentioned values are dimensionless. The practical range for the Reynolds number is between 2320 and $10^{8}$ while range for the relative roughness is between $10^{-6}$ and 0.05 .

The unknown friction factor cannot be extracted from the Colebrook equation in explicit way with no approximation involved (exception is approach with the Lambert W-function, but even then further evaluation of this function is approximate [3-7]). Therefore, the Colebrook equation has to be solved in an iterative procedure, which is the main reason that numerous explicit approximations have been developed by many authors [8-10]. A number of alternatives to the Colebrook equation along with a discussion about their use are provided in Giustolisi et al. [11]. The Colebrook equation is also used as the base for the turbulent part of the widely known Moody plot [12].

In this preliminary paper, two new very accurate approximations are presented (in addition to this preliminary paper improvement of coefficients for all other available approximations of Colebrook's equation is planned to be shown in the future). This two new improved 
approximations shown here, were developed using the genetic algorithm technique for

optimization of parameters in the already existing models proposed by Serghides in 1984 [13] and Romeo et al. in 2002 [14]. Genetic algorithms are one of the evolutionary computational intelligence techniques inspired by Darwin's theory of biological evolution [15]. They provide solutions for different types of problems, searching the most suitable among chromosomes that make the population in the potential solutions space, which makes them suitable even for difficult problems of finding the global optimum for nonlinear and multimodal optimization problems (e.g. gene expression programming analysis of implicit Colebrook's equation in turbulent flow friction factor calculation can be found in Samadianfard [16]).

\section{Elaboration of error}

All errors shown in this paper are calculated using iterative solution where the coefficients in the Colebrook equation are 2.51 and 3.71. Used relative error is defined as $\left[\left(\lambda-\lambda_{0}\right) / \lambda_{0}\right] \cdot 100 \%$, where $\lambda_{0}$ is assumed as the accurate friction factor that is obtained from iterative solution of the explicit Colebrook equation while $\lambda$ is friction factor calculated using the selected explicit approximation of the Colebrook equation. The iterative solution of the implicit Colebrook equation after sufficient number of iterations can be used for further comparisons as the most accurate. This approach is used in this paper for the evaluation of the accuracy of the explicit approximations of the Colebrook equation, i.e. for the calculation of $\lambda_{0}$. The iterative solution is obtained after 32767 iterative cycles which is more than enough (required number of iteration is usually no more than ten) [9]. Also, Matlab was used for the optimization of the parameters of the models A and B shown in the next section of this paper (e.g. a Matlab code for the calculation of Colebrook's flow friction can be found in Clamond [17]). The Matlab 
codes provided in next section were used to evaluate $\lambda$ using approximations with improved parameters presented here.

Of course, the Colebrook equation is empirical, where the numerical constants 2.51 and 3.71 were obtained by numerical fitting from the experimental data. Sometimes constant 3.71 can be changed with 3.7 (as is in original paper by Colebrook [1]). This change produces deviation of $0.138 \%$. To date, the most accurate approximations to the explicit Colebrook equation has the relative error in range between $0.13 \%$ and $0.15 \%$ [8]. This error is very small and it is in the margin of the error caused by changed coefficient 3.7 to 3.71 . On the other hand, American Gas Association (AGA) recommended use of coefficient 2.825 instead of 2.51 for calculation of flow of natural gas through pipes [8]. This causes deviation of even $3.2 \%$.

As already noted, the Moody chart [12] was developed using Colebrook's equation [1] and not opposite. Using Moody's chart for the estimation of error instead of the iterative solution of the implicit Colebrook equation, i.e. using different digitalization techniques for determination of $\lambda_{0}$ introduces additional errors in calculation [18-20]. The methodology for estimation of error is the same as from the study of Brkic [8]. Other papers with the related estimation of error are also available [10, 16, 18, 20-22].

It should be noted that the relative error changes dramatically over the domain of relative roughness and the Reynolds number [8]. The error shown here is the maximal relative error over the entire practical range for the Reynolds number from 2320 to $10^{8}$ and for the relative roughness ranging from $10^{-6}$ to 0.05 . This area is covered with 740 points uniformly sampled over the ranges of input variables, which means that estimated error can be slightly above 
(somewhere among four adjacent tested points of the matrix which consists of 740 points).

Also it has to be noted that uniform sampling might sometimes result into misleading conclusions [11].

\section{Proposed explicit approximations}

As noted in the study by Brkić [8], the five most accurate approximations to the Colebrook equation are by Vatankhah and Kouchakzadeh from 2008 [23, 24], Buzzelli from 2008 [25], Romeo et al. from 2002 [14], Serghides from 1984 [13], and by Zigrang and Sylvester from 1982 [26]. They are with the maximal relative error of no more than $0.15 \%$ [8].

Using the existing model for approximations proposed by Serghides in 1984 [13] and Romeo et al. in 2002 [14], two new approximations with optimized parameters will be introduced. Respectively, the first one, here labeled as the model A, is now with the relative error of no more than $0.0026 \%$ while the second one, labeled as model $\mathrm{B}$, is with the relative error of no more than $0.0083 \%$. This means that the relative error is decreased from $0.1385 \%$ to only $0.0026 \%$ for the model $\mathrm{A}$, and from $0.1345 \%$ to only $0.0083 \%$ for the model B.

3.1. Model A. Model A (2) is proposed by Serghides [13] and his coefficients are changed here using genetic algorithms techniques. His model is with three internal cycles additionally accelerated by Steffensen's method [27]. Coefficient 12 is changed to 12.585 while 3.7 is changed to 3.71, compared to original approximation [13].

$$
\lambda \approx\left(\mathrm{S}_{1}-\frac{\left(\mathrm{S}_{2}-\mathrm{S}_{1}\right)^{2}}{\mathrm{~S}_{3}-2 \cdot \mathrm{S}_{2}+\mathrm{S}_{1}}\right)^{-2}
$$

Where $S_{1}$ is (3): 


$$
S_{1}=-2 \cdot \log _{10}\left(\frac{\varepsilon}{3.71 \cdot D}+\frac{12.585}{\operatorname{Re}}\right)
$$

Where $S_{2}$ is (4):

$$
S_{2}=-2 \cdot \log _{10}\left(\frac{\varepsilon}{3.71 \cdot D}+\frac{2.51 \cdot S_{1}}{\operatorname{Re}}\right)
$$

And finally, where $S_{3}$ is (5):

$$
S_{3}=-2 \cdot \log _{10}\left(\frac{\varepsilon}{3.71 \cdot D}+\frac{2.51 \cdot S_{2}}{\operatorname{Re}}\right)
$$

Distribution of error for the model A approximation is shown in figure 1.

Figure 1. Distribution of error for the model A approximation

Matlab code for the model A with the improved parameters is given between the next two dash lines:

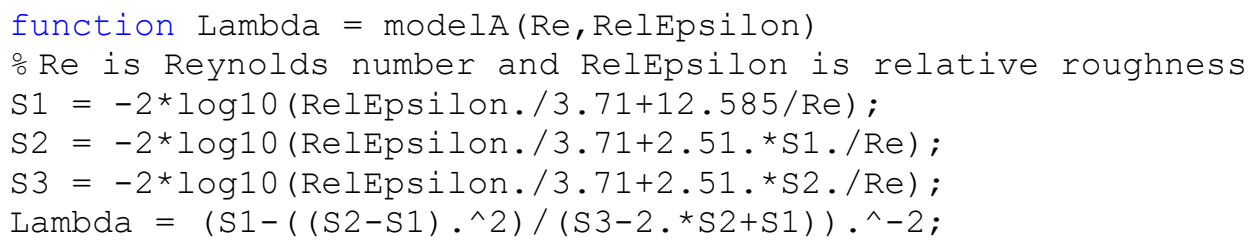

3.2. Model B. Model B (6) is proposed by Romeo et al. [14] and their coefficients are also changed here using genetic algorithms techniques. Approximation by Romeo et al. [14] is similar with the model proposed by Zigrang and Sylvester [26] with three internal cycles and with the model proposed by Chen [28] with two internal cycles. In model B, coefficient 3.7065 is changed to 3.7106 , coefficient 5.0272 to 5 , coefficient 3.827 to 3.8597 , coefficient 
4.567 to 4.795 , coefficient 7.7918 to 7.646 , exponent 0.9924 to 0.9685 , coefficient 5.3326 to 4.9755, addend 208.815 to 206.2795 and finally exponent 0.9345 to 0.8759 , compared to original approximation [14].

$$
\frac{1}{\sqrt{\lambda}} \approx-2 \cdot \log _{10}\left(\frac{\varepsilon}{3.7106 \cdot D}-\frac{5}{\operatorname{Re}} \cdot \log _{10}\left(\frac{\varepsilon}{3.8597 \cdot D}-\frac{4.795}{\operatorname{Re}} \cdot \log _{10}\left(\left(\frac{\varepsilon}{7.646 \cdot D}\right)^{0.9685}+\left(\frac{4.9755}{206.2795+\operatorname{Re}}\right)^{0.8759}\right)\right)\right)
$$

Distribution of error for the model B approximation is shown in figure 2.

Figure 2. Distribution of error for the model A approximation

Matlab code for the model B with the improved parameters is given between the next two dash lines:

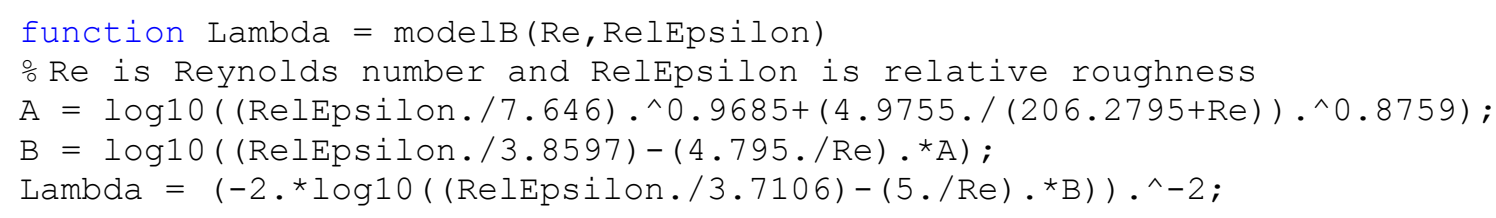

As already noted, and as also can be seen from figures 1 and 2, relative error is not uniformly distributed. This fact is characteristic of all available explicit approximations of the Colebrook equation [8].

\section{Comparative analysis}


Using model A and parameters improved by genetic algorithm optimization technique, maximal relative error decreased 53.26 times compared to coefficients proposed by Serghides [13]. Using model B and the same optimization technique, the relative error decreased 16.2 times compared to the parameters proposed by Romeo et al. [14]. Improvement best can be seen from figure 3 .

Figure 3. Improvement of coefficients in the existing models A and B using genetic algorithm optimization technique

\section{Conclusion}

Existing approximations of the Colebrook equation are complex by the rule. Some of them even look simple, but essentially they are not since they contain non-integer exponent or many logarithmic expressions [17]. The computation of logarithm in many computer languages is based on series expansions that require several powers of the argument to be computed and added to each other. In particular, all of them require the computation of some logarithms to achieve a sufficiently accurate solution, without caring how such an operation may affect real computer applications [22]. In this paper, observed models were not simplified, but the accuracy of approximations has been increased by improving parameters using genetic optimization technique, namely 53.26 times when the model $\mathrm{A}$ is used and 16.2 times when the model B is used (genetic algorithms can be also successfully used in other branches of engineering $[29,30])$. In other words, computational burden stays unchanged compared with the approximations by Serghides [13] and Romeo et al. [14], but accuracy of these model increases with the introduction of here presented new parameters [31]. Additionally, curve fitting or surface fitting tool from Matlab can be used for fine tuning of coefficients after improvements made using genetics algorithm optimization techniques [23, 
24]. Using only fitting tool of Matlab (with no use of genetic algorithms), Vatankhah and Kouchakzadeh [23, 24] improved coefficients from the approximation of Sonnad and Goudar $[32,33]$ (in that way maximal relative error decrease from $0.8003 \%$ to $0.1472 \%$ ).

Beyond the most accurate optimized approximations that we have presented here, genetic optimization methodology can be applied to the wider set of the approximations for explicit pipe flow friction calculation published to date, in order to offer improved accuracy with possibly other computational benefits.

\section{Acknowledgement}

The work of Žarko Ćojbašić was partially supported by the research grant No. TR35016 from the Ministry of Education and Science of Republic of Serbia. The work of Dejan Brkić was supported by the research grant No. 11-51-2322/2012-03 from the Provincial Secretariat for Science and Technological Development of Autonomous Province of Vojvodina (Republic of Serbia).

\section{References:}

[1] C.F. Colebrook, Turbulent flow in pipes with particular reference to the transition region between the smooth and rough pipe laws, J. Inst. Civil. Eng. (London) 11(4) (1939) 133-156. [2] C.F. Colebrook, C.M. White, Experiments with fluid friction in roughened pipes, Proc. Roy. Soc. Ser. A Math. Phys. Sci. 161(906) (1937) 367-381.

[3] D. Brkić, W solutions of the CW equation for flow friction, Appl. Math. Lett. 24(8) (2011) 1379-1383.

[4] G. Keady, Colebrook-White formula for pipe flow, J. Hydr. Eng. ASCE 124(1) (1998) 9697. 
[5] A.A. More, Analytical solutions for the Colebrook and White equation and for pressure drop in ideal gas flow in pipes, Chem. Eng. Sci. 61(16) (2006) 5515-5519.

[6] J.R. Sonnad, C.T. Goudar, Constraints for using Lambert W Function-based explicit Colebrook-White equation, J. Hydr. Eng. ASCE 130(9) (2004) 929-931.

[7] D. Brkić, Comparison of the Lambert W-function based solutions to the Colebrook equation, Eng. Computation 29(6) (2012) 617-630.

[8] D. Brkić, Review of explicit approximations to the Colebrook relation for flow friction, J. Petrol. Sci. Eng. 77(1) (2011) 34-48.

[9] D. Brkić, Determining friction factors in turbulent pipe flow, Chem. Eng. (New York) 119(3) (2012) 34-39.

[10] G.A. Gregory, M. Fogarasi, Alternate to standard friction factor equation, Oil Gas J. 83(13) (1985) 120, 125-127.

[11] O. Giustolisi, L. Berardi, T.M.Walski, Some explicit formulations of Colebrook-White friction factor considering accuracy vs. computational speed, J. Hydroinf. 13(3) (2011) 401418.

[12] L.F. Moody, Friction factors for pipe flow, Trans. ASME 66(8) (1944) 671-684.

[13] T.K.Serghides, Estimate friction factor accurately, Chem. Eng. (New York) 91(5) (1984) 63-64.

[14] E. Romeo, C. Royo, A. Monzon, Improved explicit equation for estimation of the friction factor in rough and smooth pipes, Chem. Eng. J. 86(3) (2002) 369-374.

[15] D.E. Goldberg, Genetic algorithms in search, optimization and machine learning, 1st ed., Addison-Wesley Inc, Reston, 1989.

[16] S. Samadianfard, Gene expression programming analysis of implicit Colebrook-White equation in turbulent flow friction factor calculation, J. Petrol. Sci. Eng. 92-93 (2012) 48-55. 
[17] D. Clamond, Efficient resolution of the Colebrook equation, Ind. Eng. Chem. Res. 48(7) (2009) 3665-3671.

[18] G. Y1ldırım Computer-based analysis of explicit approximations to the implicit Colebrook-White equation in turbulent flow friction factor calculation, Adv. Eng. Softw. 40(11) (2009) 1183-1190.

[19] D. Brkić, New explicit correlations for turbulent flow friction factor, Nucl. Eng. Des. 241(9) (2011) 4055-4059.

[20] X. Fang, Y. Xu, Z. Zhou, New correlations of single-phase friction factor for turbulent pipe flow and evaluation of existing single-phase friction factor correlations, Nucl. Eng. Des. 241(3) (2011) 897-902.

[21] D.J. Zigrang, N.D. Sylvester, A review of explicit friction factor equations, J. Energ. Resour. ASME 107(2) (1985) 280-283.

[22] F. Abdolahi, A. Mesbah, R.B. Boozarjomehry, W.Y. Svrcek, The effect of major parameters on simulation results of gas pipelines, Int. J. Mech. Sci. 49(8) (2007) 989-1000. [23] A.R. Vatankhah, S. Kouchakzadeh, Discussion of "Turbulent flow friction factor calculation using a mathematically exact alternative to the Colebrook-White equation" by Jagadeesh R. Sonnad and Chetan T. Goudar, J. Hydraul. Eng. ASCE 134(8) (2008) 1187. [24] A.R. Vatankhah, S. Kouchakzadeh. Discussion: Exact equations for pipe-flow problems, by P.K. Swamee and P.N. Rathie, J. Hydraul. Res. IAHR 47(7) (2009) 537-538.

[25] D. Buzzelli, Calculating friction in one step, Mach. Des. 80(12) (2008) 54-55.

[26] D.J. Zigrang, N.D. Sylvester, Explicit approximations to the solution of Colebrook friction factor equation, AIChE J. 28(3) (1982) 514-515.

[27] L.W. Johnson, D.R. Scholz, On Steffensen's method, SIAM J. Num. Anal. 5(2) (1968) 296-302. 
[28] N.H. Chen, An explicit equation for friction factor in pipes, Ind. Eng. Chem. Fundam. $18(3)$ (1979) 296-297.

[29] M. Ristanović, Ž. Ćojbašić, D. Lazić, Intelligent control of DC motor driven electromechanical fin actuator, Control Eng. Pract. 20(6) (2012) 610-617.

[30] Ž. Ćojbašić, V. Nikolić, I. Ćirić, Lj. Ćojbašić, Computationally intelligent modeling and control of fluidized bed combustion process, Therm. Sci.15(2) (2011) 321-338.

[31] M. Danish, S. Kumar, S. Kumar, Approximate explicit analytical expressions of friction factor for flow of Bingham fluids in smooth pipes using Adomian decomposition method, Commun. Nonlinear. Sci. Numer. Simulat. 16(1) (2011) 239-251.

[32] J.R. Sonnad, C.T. Goudar, Turbulent flow friction factor calculation using a mathematically exact alternative to the Colebrook-White equation, J. Hydraul. Eng. ASCE $132(8)(2006) 863-867$.

[33] J.R. Sonnad, C.T. Goudar, Explicit reformulation of the Colebrook-White equation for turbulent flow friction factor calculation, Ind. Eng. Chem. Res. 46(8) (2007) 2593-2600. 
Model A, eq. (2)

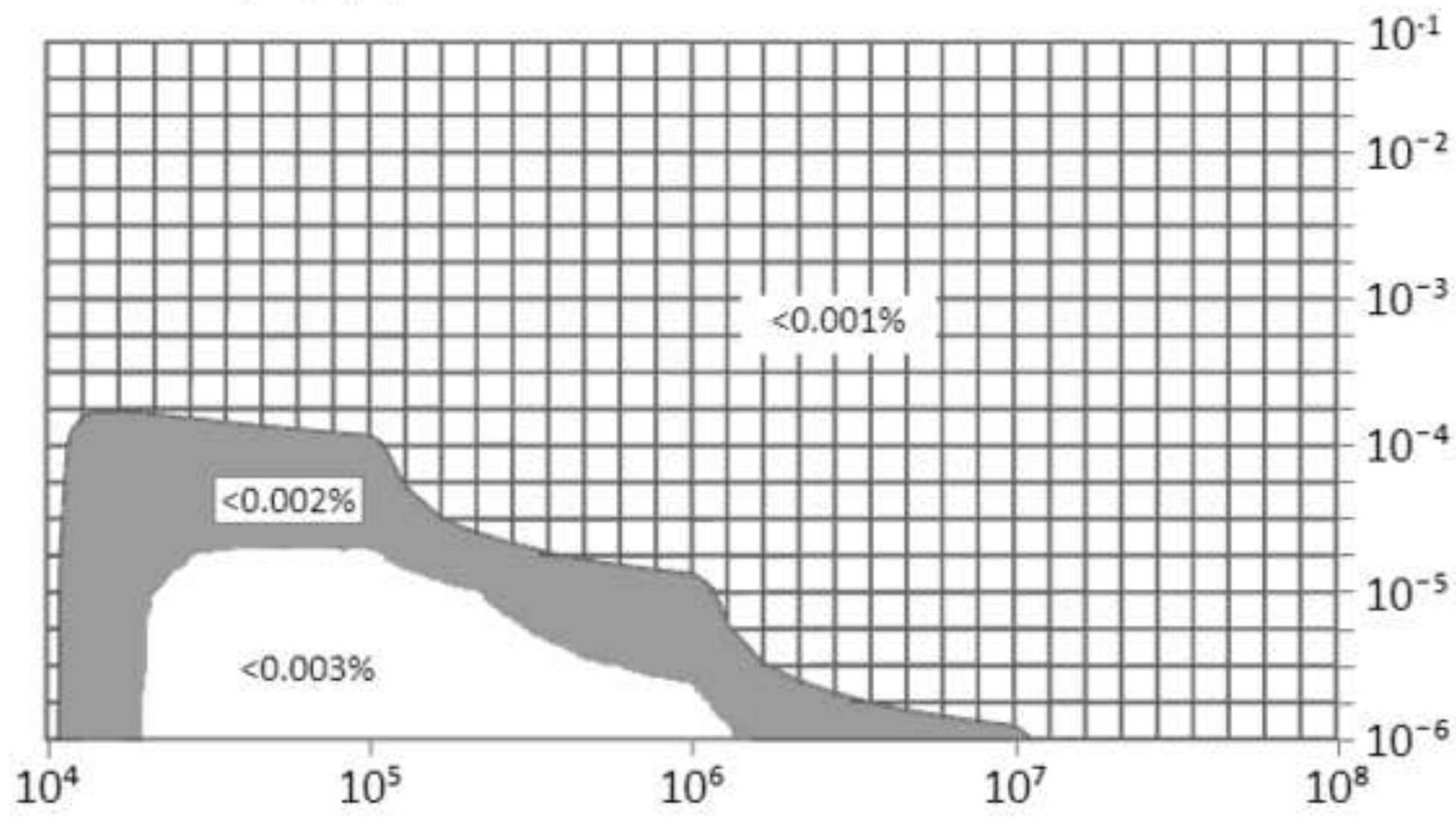

$\square 0.002-0.003 \%$ $0.001-0.002 \%$ $\boxplus 0.000-0.001 \%$

Reynolds number: $\operatorname{Re}$ 
Model B, eq. (6)

$\leq 0.0083 \%$ Relative roughness: $\varepsilon / D$

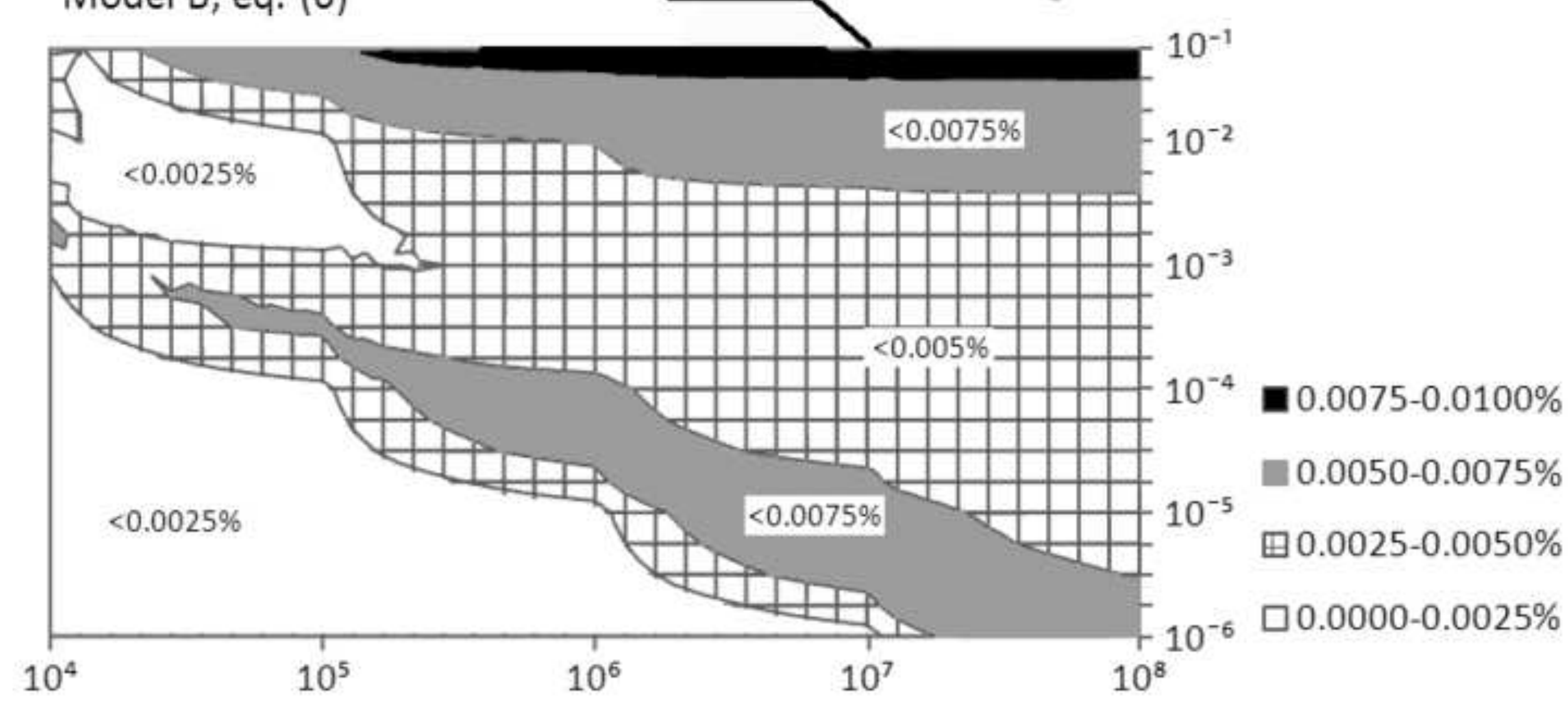

- $0.0075-0.0100 \%$ 0.0050-0.0075\% $\boxplus 0.0025-0.0050 \%$ 口0.0000-0.0025\%

Reynolds number: Re 


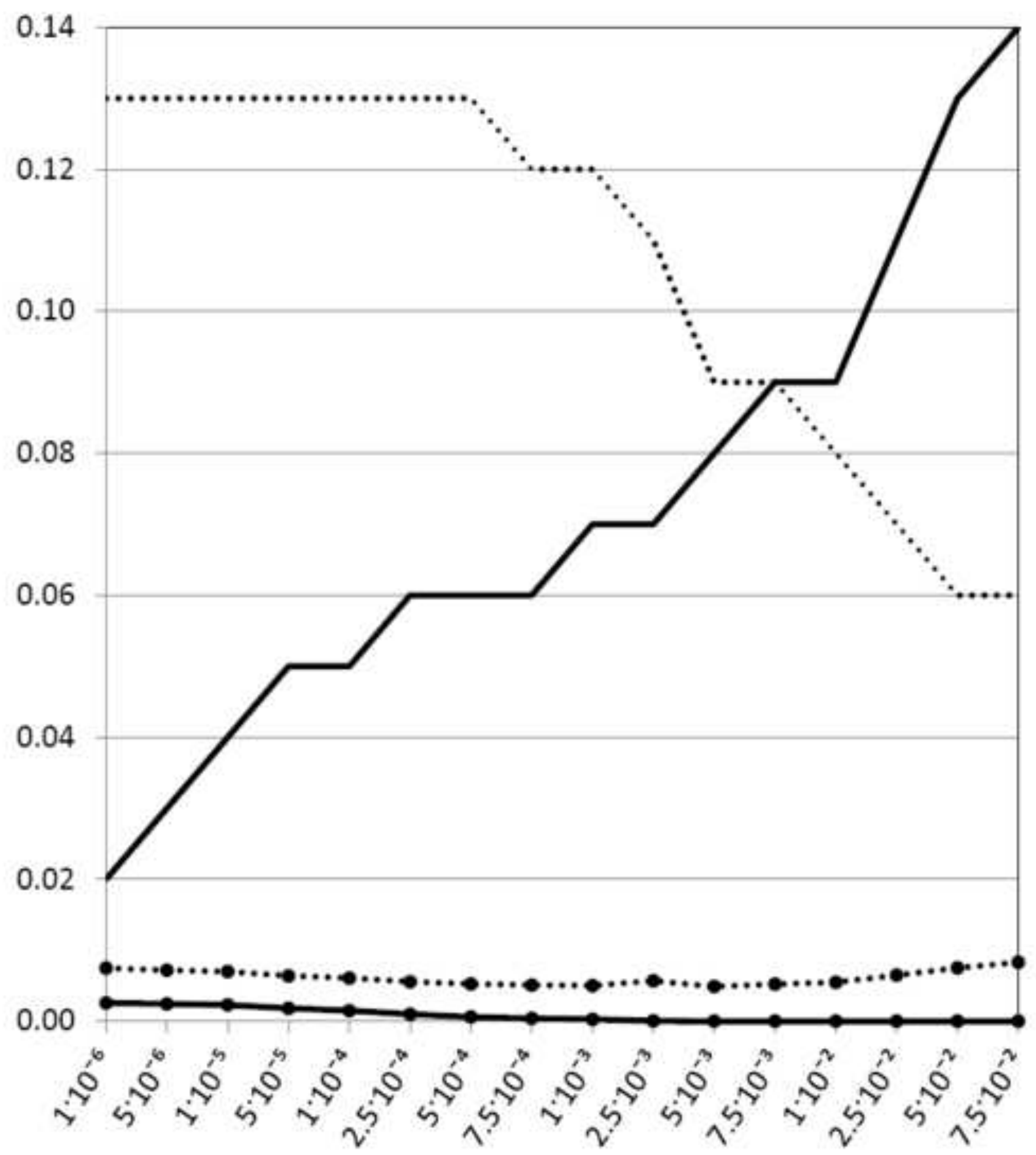

Relative roughness $(\varepsilon / D)$

— Model A, Serghides

$\longrightarrow$ Model A, Eq. (2)
...... Model B, Romeo et al.

•.. Model B, Eq. (6) 